\title{
Sciendo
}

Administration, vol. 69, no. 3 (2021), pp. 101-105

doi: 10.2478/admin-2021-0023

\section{Cities and communities beyond COVID-19: How local leadership can change our future for the better}

Robin Hambleton (Bristol: Bristol University Press; 2020; ISBN: 9781-529215-85-4; $171 \mathrm{pp}$; 9.99 )

Can the shock of the Covid-19 pandemic open our eyes to new possibilities? What kind of future do we want for ourselves and our children? How ought we govern ourselves? Is the continued exploitation of people and the planet the right path for modern societies? These are just a few of the questions Robin Hambleton poses at the outset of Cities and Communities Beyond COVID-19. With these, the reader is almost immediately confronted with their own predispositions and ideologies as they dive deeper into the text. Hambleton is careful not to suggest any one answer to these questions; rather he contends that the answers lie in the specificities of different communities. The very idea of 'best practice', he contends, should indeed be done away with and be replaced instead by 'relevant practice' (p. 136).

The structure of the chapters are reminiscent of that of a text book: introduction, body, conclusion. Hambleton manages to make relatively complex topics accessible in providing definitions of jargon and providing introductory sections to difficult topics to ensure readers have the same baseline information. An introductory section, for instance, is provided for 'understanding modern leadership' in Chapter One, which offers definitions of 'leadership' by several academics and a rather humorous comparison of the leadership styles of New Zealand Prime Minister Jacinda Ardern and previous US President Donald Trump. Although at times the book is slightly repetitive, this serves to reiterate and reinforce key points and ideas, once more mimicking a text book, which increases its accessibility to readers from all walks of life and makes it easy to identify key points to refer back to later. This book would be of interest to anyone 
affected by Covid-19 (so everyone!), and particularly those involved in or passionate about public policy, reform, local governance, the climate crisis, systemic racism and social inequality.

Although the book makes use of several international case studies and examples, it largely focuses on the UK context. Special attention is allocated to the progressive and effective innovations within Bristol's local authority as well as its incumbent mayor, Marvin Rees. Historical facts are dotted throughout the book, making for a fascinating read and breaking up the otherwise jam-packed text on policy. Hambleton makes use of quotes and insights from various academics from disparate spheres to help frame different debates. In employing the knowledge of different experts from a range of disciplines, the author increases the validity of the text, as well as providing a holistic perspective on the issues at hand. Featuring of particular note are world-renowned philosopher and writer Michel Foucault, science journalist Laura Spinney, philosopher Jean-Jacques Rousseau, scientist and environmentalist James Lovelock, and writer and activist Rachel Carson.

A significant emphasis is placed on the important role to be played by local government in the post-Covid-19 world. Citing the work of Lucy Jones, a seismologist with the US Geological Survey, Hambleton notes 'how many of the most important actions that a community can take can happen in local government' (p. 17). Later he argues that Covid-19 has served as a reminder that the building blocks of civil society - reciprocity, cooperation, association, connection, solidarity and community - are, on the whole, place-based and local. In Chapter Three, Hambleton poses the question: what is local government for? Here the reader is encouraged into thinking about their own ideas regarding local governance before the text's discussion, which enables comparative thought and potential for greater learning in the mind of the reader. This emphasis on the role of governance presents an important and valuable learning opportunity for Ireland in moving forward with pandemic recovery plans.

Ultimately, Hambleton advocates for the necessity to use the momentum for policy reform post Covid to tackle other important policy issues: 'effective responses to the Covid-19 pandemic need to address - at the same time - pre-existing challenges relating to, for example, the climate change emergency, corrosive social inequality, and systemic racism' (p. 134). Hambleton cites Mark Honigsbaum, from his book The Pandemic Century, explaining that time and again the exploitation of the planet has disturbed the ecological equilibrium 
in which pathogens reside and, in turn, these disruptions have exacerbated the spread and severity of zoonotic diseases to humans, resulting in epidemics and pandemics (p. 28). Thus, steps to prevent future pandemics must be closely aligned with efforts to address the climate crisis. According to Hambleton, pandemics and the climate crisis alike have arisen from the misguided behavior of humans: 'we are the architects of our own suffering' (p. 153). Fortunately, this means that by modifying our own public policies, practice and behaviours, we have the opportunity to alter the blueprint of our future.

Covid-19, Hambleton expounds, is having a profoundly uneven impact on different groups in society. While Covid-19 certainly stands as a global threat to all, it simultaneously discriminates in a brutal way. Hambleton demonstrates that those living in the poorest areas of England and Wales were dying at twice the rate of those living in lessdeprived areas during the period from March to April 2020. This observation, made by the author in early 2020, is indicative of the larger inequalities that have emerged over the last year since publication. Developing countries are struggling more than their developed counterparts with the virus, and evidence shows that black and brown communities have been more adversely affected than white communities (Bowleg, 2020; Krieger, 2020). On top of all of this, those inequalities are further exposed by the disproportionate numbers of vaccines being bought up by rich countries, leaving many poorer countries still awaiting their first dose (Vaughan, 2021). This persistent inequality and unfairness, Hambleton argues, threatens the stability of some Western democracies. Hambleton points at the Black Lives Matter movement not only as an example of such destabilisation but also as an example place-based power and movements.

Despite the fact that the book is about very serious issues for which we are on the wrong policy trajectory globally, this book is refreshingly optimistic. Hambleton writes of political possibilities and windows of opportunity. He posits that New Civic Leadership, which is committed to advancing the power of place-based communities rather than placeless actors, could be a good alternative to New Public Management, whose prioritisation of privatisation, marketisation and treatment of citizens as consumers has been shown to have serious limitations (pp. 90-1). This is also captured well in the sixth chapter, in which Hambleton presents 'innovation cameos': five examples of international place-based innovative leadership (p. 138). Operationalising these 'innovation cameos' from local authorities, he points 
attention to policies and plans that have taken place at the local authority level which owe their success to inventive local leaders and governments who have been granted the autonomy to come up with localised solutions to certain problems. The profoundly successful cycling schemes in Copenhagen comprise one such 'cameo' (p. 139). The book also offers suggestions and pointers which aim to prompt fresh thinking when it comes to possibilities for an altogether better post-Covid world. One suggestion of particular note is for the UK to hold constitutional conventions (p. 159) - something we, in Ireland, are known for.

There is a dichotomy present throughout the text between placebased and place-less power, which are, more often than not, at odds with each other. Place-less decision makers are often found in big multinational companies, typically driven by narrow calculations regarding private profit growth, or in centralised government departments, where some politicians seek to play places off against each other instead of having a wider societal purpose. Physically and emotionally removed from the impacted communities, place-less power is argued in this book to be the chief obstacle in the path of those who want to advance the cases of public health and economic, social and environmental justice in the modern world. To take decisions without caring about the subsequent impacts for communities is not only morally wrong, Hambleton argues, but economically unwise, socially destructive and environmentally disastrous. In fact, the book claims that powerful place-less actors played a major role in promoting the conditions that led to this pandemic.

For this reason, there is a need to acknowledge, foster and expand the power of place. Place-based leadership can tap into local energies and passions that are not available to place-less actors or distant national governments. Hambleton explains that, during the current health crisis, local leaders have been able to exercise vital leadership roles in three primary ways: firstly, in directing citizens to accurate information; secondly, in taking action to address particular concerns relating to vulnerable groups in the population; and thirdly, in working with a variety of civil society organisations and citizens to devise collaborative community-based solutions. There is therefore an essential role and significant untapped potential in place-based leadership to help us co-create a post-Covid world that is guided by progressive values which promote participatory decision-making and aim to advance social, economic and environmental justice (p. 63). 
The opening chapter of the book is appropriately titled 'No Going Back'. At a time in which the dominant global discourse perpetuates an idea of 'getting back to normal', this concept is more important than ever. Hambleton calls for better far-sightedness and the incorporation of the value of caring as a key component in order to make meaningful, effective and just policy. The evidence in this book demonstrates that governance matters. Having strong local governance structures in place before, during and after a disaster like a pandemic saves lives and underpins societal recovery (pp. 127-8). Therefore, it is crucial that we make better use of local leadership by granting local governments more autonomy and scope to find contemporary and creative solutions to the crises at hand. Given the fact that they are in a unique position to tap into local knowledge, solutions generated by local authorities are likely to be more specific and targeted to the region and therefore perhaps more effective. Most importantly, we must not revert back to 'normal': 'if we want to protect ourselves against future disasters, if we want to promote fairness in society, support humans flourishing and defeat the threat of global warming, there can be "no going back" (p. 165).

\section{References}

Bowleg, L. (2020). We're not all in this together: On COVID-19, intersectionality, and structural inequality. American Journal of Public Health, 110 (7), 917.

Krieger, N. (2020). ENOUGH: COVID-19, structural racism, police brutality, plutocracy, climate change-and time for health justice, democratic governance, and an equitable, sustainable future. American Journal of Public Health, 110 (11), 1620-3.

Vaughan, A. (2021). Global vaccine inequality. New Scientist, 249 (3320), 12-13.

\section{Naomi Blumlein}

